TITLE:

\title{
ON THREE NEW SPECIES OF CUMACEAN CRUSTACEA GENUS CAMPYLASPIS FROM TANABE BAY, KII PENINSULA
}

\author{
$\operatorname{AUTHOR}(\mathrm{S})$ : \\ Gamo, Sigeo
}

\section{CITATION:}

Gamo, Sigeo. ON THREE NEW SPECIES OF CUMACEAN CRUSTACEA GENUS CAMPYLASPIS FROM TANABE BAY, KII PENINSULA. PUBLICATIONS OF THE SETO MARINE BIOLOGICAL LABORATORY 1960, 8(1): 153-161

\section{ISSUE DATE:}

1960-05-30

URL:

http://hdl.handle.net/2433/174694

RIGHT: 


\title{
ON THREE NEW SPECIES OF CUMACEAN CRUSTACEA GENUS CAMP YLASPIS FROM TANABE BAY, KII PENINSULA ${ }^{13}$
}

\author{
Sigeo GAMÔ \\ Faculty of Liberal Arts and Education, Yokohama \\ National University, Kamakura, Kanagawa-ken
}

With 6 Text-figures

The present paper deals with three new species of cumacean Crustacea, Campylaspis kiiensis sp. nov., C. granulata sp. nov. and C. pumila sp. nov. (Nannastacidae), which were found in a small collection of Cumacea obtained from Tanabe Bay, Kii Peninsula.

I wish to express my sincere thanks to Professor Tune SakaI for his guidance and to Dr. Huzio Utinomi of the Seto Marine Biological Laboratory for giving me an opportunity of studying this material. And also thanks are due to Professor Masao IwASA of the Seikei University for his much helps and valuable advices.

\section{Campylaspis kiiensis sp. nov.}

(Figs. 1, 2)

Type young male specimen (length, about $2.6 \mathrm{~mm}$ ): The carapace is sparsely clothed with fine hairs and with median dorsal line. There are two pairs of pellucid spots on the antero-median portion and such a spot also on each side of frontal lobe. The length of carapace is a little less than one-half as long as the total length of animal, and one and three-fourths times as long as its greatest width, which is as long as its depth. The large ocular lobe is semicircular, one-half as long as its width and furnished with three large lenses. The antennal notch is distinct, widely open and provided with round antero-lateral angle.

The first joint of peduncle of antennule is shorter than the two distal joints together. The second joint is shorter than the third. The main flagellum has three joints. The accessory flagellum is rudimentary.

The terminal joint of first maxilliped is very minute.

1) Contributions from the Seto Marine Biological Laboratory, No. 348 .

Publ. Seto Mar. Biol. Lab., VIII (1), 1960. (Article 13) 
The distal joint of second maxilliped is provided with four spines, each about one-half as long as the distal outer spine on the penultimate joint.

The basis of third maxilliped is shorter than the remaining distal joints together, and furnished with serrations and hairs on the distal inner edge. The merus is a little shorter than the carpus, propodus and dactylus together, and furnished with seven teeth on the inner edge and four on the outer. The width of merus is two-thirds as long as its length. The carpus is about as long as the distal two joints together and provided with six teeth on the inner edge and one on the outer. The propodus is as long as the dactylus and furnished with four teeth on the inner edge and two small teeth on the outer.

The basis of first peraeopod is as long as the remaining distal joints together. The merus is as long as and as wide as the carpus. Both merus and carpus are distally expanded. The propodus is about as long as the dactylus.

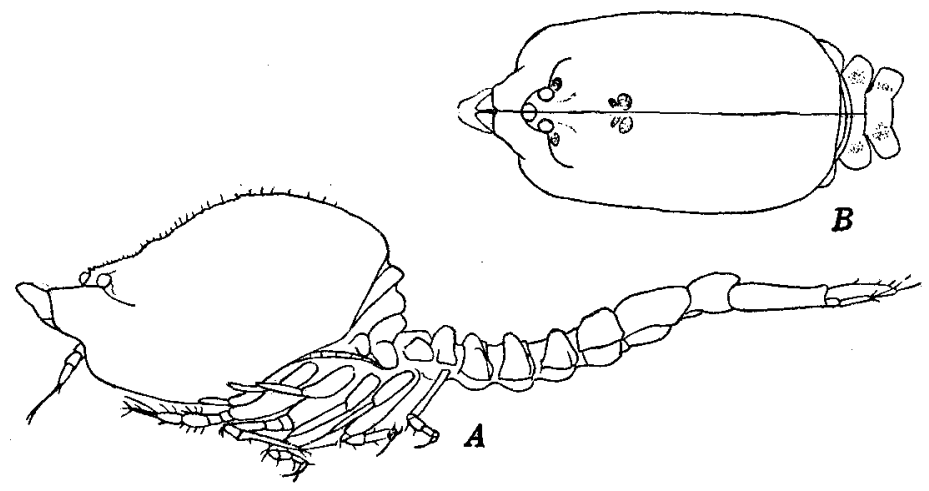

Fig. 1. Campylaspis kiiensis sp. nov., type young male.

$A$ : lateral view. $B$ : anterior portion of body, from above.

The second peraeopod is a little longer than the first. The basis is as long as the next four joints together. The dactylus is stout, as long as the carpus and furnished with a long and a short terminal setae.

The peduncle of uropod is serrate on the inner and outer edges and nearly twice as long as the sixth abdominal segment. There are about four spinules on the inner edge and about five small hairs on the outer. The peduncle is much less than twice as long as the endopod. The endopod and has two short and a long terminal spines and serrations on the outer edge, and three spines interspaced with two or three spinules on the inner edge. The exopod is shorter than the endopod and furnished with a long and a short terminal spines and a lateral spine on the inner edge.

Remarks: The new species may be distinguished from four related species, such as C.thompsoni, C. similis (HALE '45), C. glabra and C. rubicunda (SARS 1900) 
by having the short dactylus of second peraeopod with a long terminal seta and a deep antennal notch.

Occurrence: 1 s (type young specimen). Tanabe Bay.

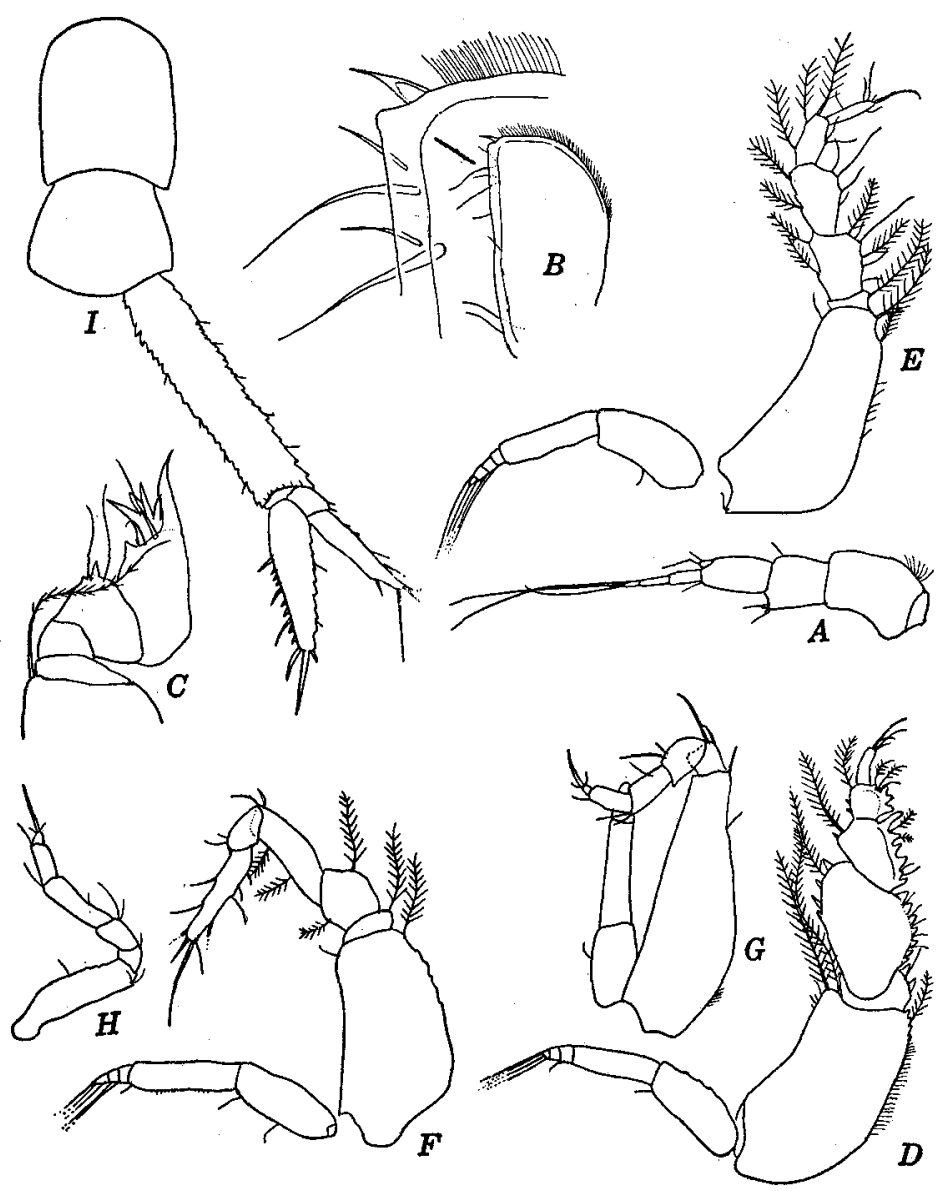

Fig. 2. Campylaspis kiiensis sp. nov., type young male.

$A$ : antennule. $B-C$ : distal portion of first and second maxillipeds. $D$ : third maxilliped. $E-G$ : first to third peraeopods. $H$ : fifth peraeopod. $I$ : uropod with fifth and sixth abdominal segments.

2. Campylaspis granulata sp. nov.

(Figs. 3, 4)

Type young female specimen (length, about $2.7 \mathrm{~mm}$ ): The carapace is sparsely clothed with fine hairs and furnished with about twenty pellucid spots 
on the anterior portion and with the median dorsal line. There are minute spaced granules and an elongate faint depression on each side, which is margined by rows of granules. The length of carapace is slightly less than one-half of the total length of animal and about one and one-half times as long as its width, which is less than its depth. The pseudorostral lobes are somewhat pointed in front, meeting for a distance about equal in length to the semicircular ocular lobe, which is twice as wide as its length. The antennal notch is slightly distinct and provided with the round antero-lateral angle.

The first joint of peduncle of antennule is much shorter than the distal two joints together. The second is shorter than the third. The main flagellum has three joints and the accessory flagellum is rudimentary.

The distal joint of first maxilliped is very minute and furnished with three granules on the distal end.

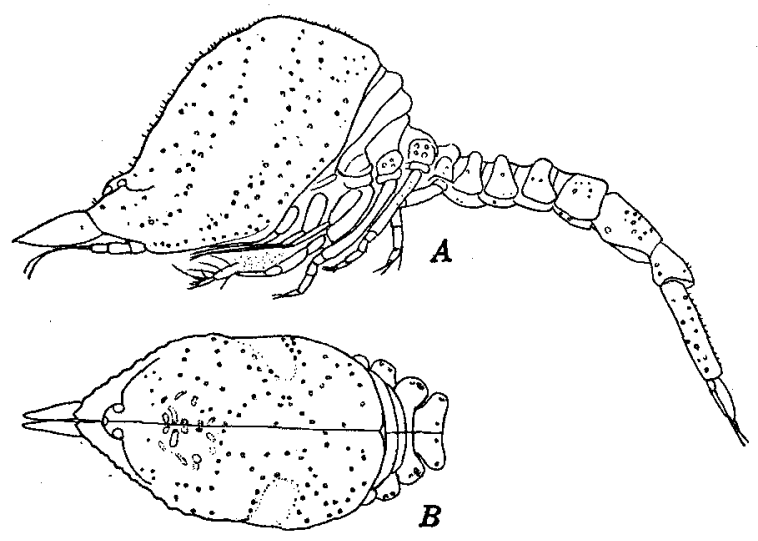

Fig. 3. Campylaspis granulata sp. nov., type young female.

$A$ : lateral view. $B$ : anterior portion of body, from above.

The distal joint of second maxilliped has four spines, each less than one-half as long as the distal outer spine on the penultimate joint.

The basis of third maxilliped is stout, about three-fifths as long as the remaining distal joints together and furnished with serrations and fine plumous hairs on the distal portion of inner edge. The merus is nearly as long as the basis and armed with nine teeth on the inner edge and three on the outer. The carpus is as long as propodus, proximally expanded and furnished with seven teeth on the inner edge and three small teeth on the outer. The propodus is more than twice as long as the dactylus and has three teeth on the proximal portion of inner and outer edges.

The basis of first peraeopod is about three-fourths as long as the remaining distal joints together and furnished with fine hairs on the inner edge. The merus 
is distally expanded and a little longer than the carpus, which is as long as the propodus. The dactylus is shorter than the propodus and furnished with a terminal hair and two long hairs on the outer edge and such a hair and fine hairs on the inner.

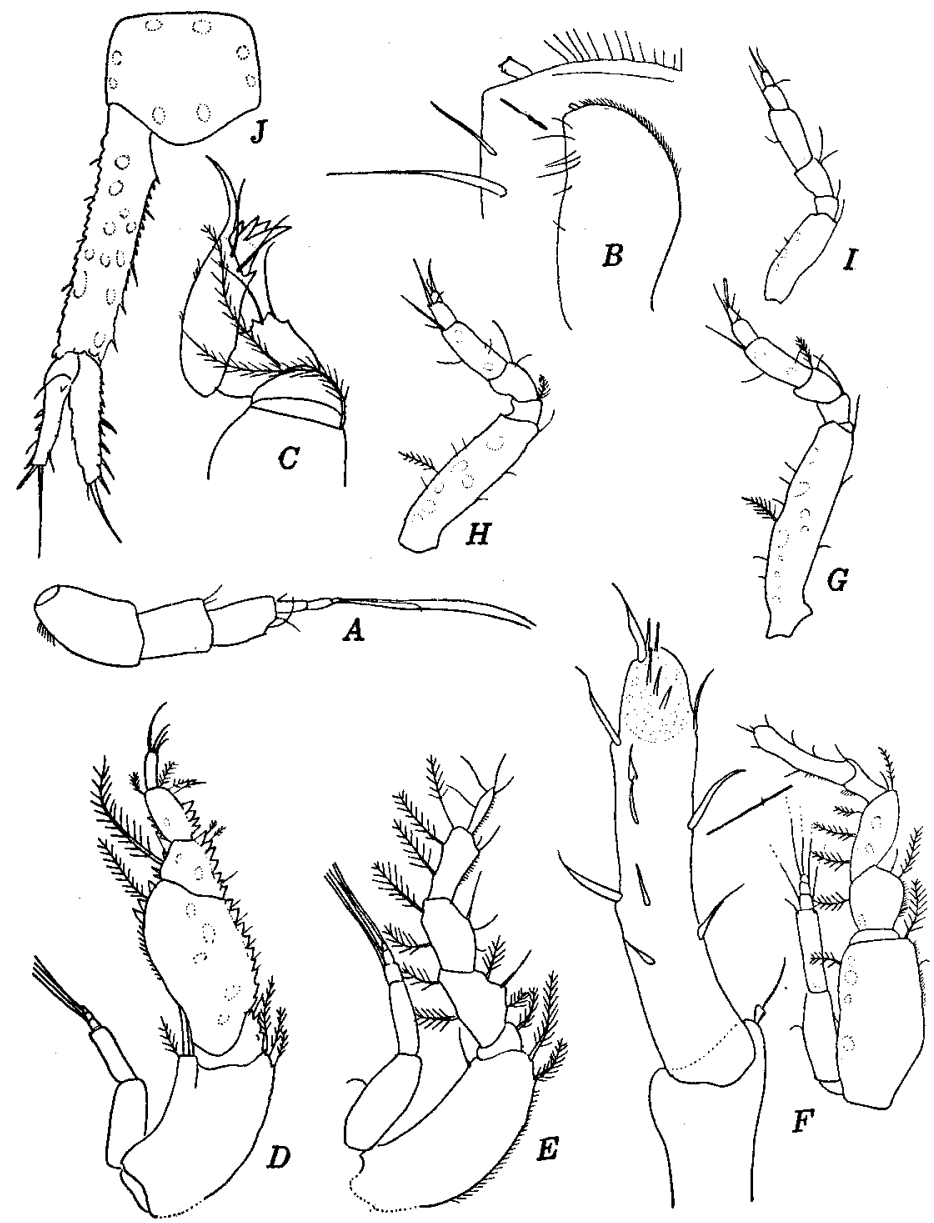

Fig. 4. Campylaspis granulata sp. nov., type young female.

$A$ : antennule. $B-C$ : distal portion of first and second maxillipeds. $D$ : third maxilliped. $E-I$ : first to fith peraeopods. $J$ : uropod with sixth abdominal segment.

The second peraeopod is about as long as the first. The basis is longer than the next four joints together. The dactylus is stout, cylindrical form with rounded end, as long as the carpus and provided with three terminal setae, one of which is twice as long as the small ones. There are three small setae on the distal 
portion and about three or four setae on the proximal portion.

The peduncle of uropod with serrations, is less than twice as long as the sixth abdominal segment. There are about four small hairs on the outer edge and four spines on the inner. The endopod with serrations, is nearly one-half as long as the peduncle and furnished with three spines on the inner edge and three terminal spines, one of which is much longer than the others. The exopod is shorter than the endopod and furnished with a spine on the inner edge, three spines and a seta on the outer and two terminal setae.

Remarks: The new species is related to C. latydactyla HAle (HALE '45) and C. canaliculata ZIMMER (ZIMMER '36).

It may be distinguished from C. latydactyla and C. canaliculata by having the carapace with spaced small granules.

Occurrence: 2 우 (1우 type specimen); 1 우, night surface plankton, 28 May, 1959. Tanabe Bay.

\section{Campylaspis pumila sp. nov.}

(Figs. 5, 6)

Type ovigerous female specimen (length, about $1.6 \mathrm{~mm}$ ): The body is not well calcified. The carapace is smooth and provided with about eleven pairs of pellucid spots on the anterior portion and with a wide, curved furrow on each side, margined by a low fold. There are four small yellowish spots on each side (two on the postero-dorsal portion and the others on the lower). The length of carapace is more than one-half as long as the total length of animal and about one and two-thirds times as long as its width, which is slightly less than its depth. The pseudorostral lobes are faintly pointed in front, meeting for a distance much greater than the length of ocular lobe. The ocular lobe is round, wider than its length, and has three small lenses. The antennal notch is faintly marked, with round antero-lateral angle. The antero-lateral or lower margin is a little serrated.

The first joint of peduncle of antennule, is about two-thirds as long as the remaining distal joints together. The second joint is shorter than the third. The main flagellum has three joints. The accessory flagellum is very minute.

The terminal joint of first maxilliped is very minute and furnished with a small hair on the distal portion.

The distal joint of second maxilliped has four spines, each spine is about one-half as long as the distal outer spine on the penultimate joint.

The basis of third maxilliped is a little expanded distally, nearly threefourths as long as the remaining distal joints together. There is a plumous hair with sparse inner branches on the external angle. The merus is as long as the 
carpus and the propodus together and furnished with six hairs on the inner edge and three teeth on the outer. The carpus is shorter than the propodus, which is twice as long as the dactylus. The carpus has three small teeth on the inner edge and a tooth on the outer. There are three small teeth on the proximal portion of inner edge of propodus.

The basis of first peraeopod is about five-sixths as long as the remaining distal joints together. The merus is about as long as the carpus, which is longer than the propodus. The dactylus is as long as the propodus.

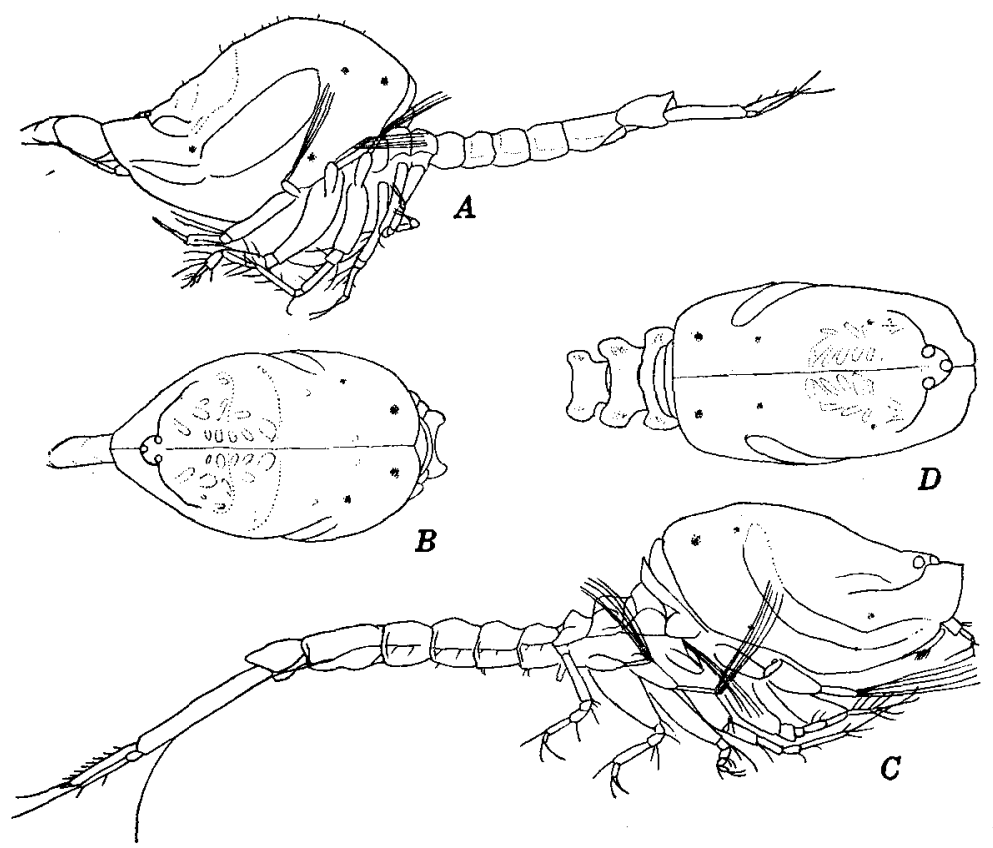

Fig. 5. Campylaspis pumila sp. nov., type ovigerous female.

$A$ : lateral view. $B$ : anterior portion of body, from above. Paratype adult male: $C$ : lateral view. $D$ : anterior portion of body, from above.

The second peraeopod is shorter than the first. The basis is longer than the ischium, merus and carpus together. The dactylus is nearly as long as the carpus and propodus together, tapering to the distal end and furnished with four terminal setae, one of which is much more than the length of dactylus and plumous at the distal portion.

The peduncle of uropod is two and one-third times as long as the sixth abdominal segment, a little serrated on the outer edge and furnished with eleven teeth on the inner. The endopod is as long as the exopod, which is a little less than one-half as long as the peduncle. The exopod is provided with a short and 


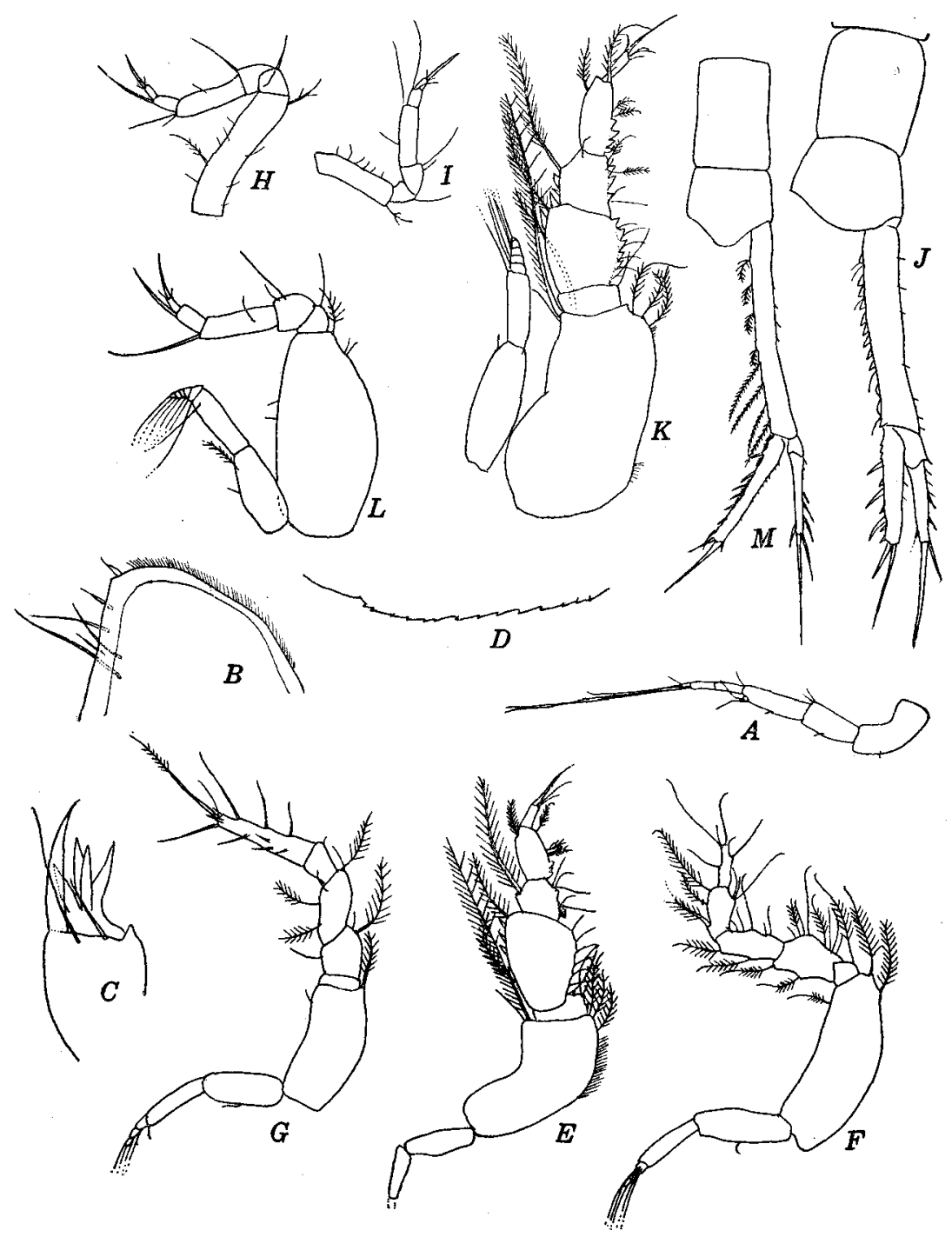

Fig. 6. Campylaspis pumila sp. nov., type ovigerous female.

$A$ : antennule. $B-C$ : anterior portion of first and second maxillipeds. $D$ : anterolateral or lower magin of carapace. $E$ : third maxilliped. $F-G$ : first and second peraeopods. $H-I$ : fourth and fifth peraeopods. $J$ : uropod with fifth and sixth abdominal segments. Paratype adult male. $K$ : third maxilliped. $L$ : fourth peraeopod. $M$ : uropod with fifth and sixth abdominal segments. 
a long terminal setae. There are about five spines on the outer edge and a seta on the inner. The endopod has a long and a short terminal setae and three teeth interspaced with one or two spines on the inner edge.

Adult male specimen (length, about $2.0 \mathrm{~mm}$ ): The carapace is more than onehalf as long as the total length of animal and one and two-thirds times as long as its width, which is a little more than its depth. The pseudorostral lobe is widely truncate, meeting for a distance about equal in length to the ocular lobe.

The basis of third maxilliped is stout, about four-fifths as long as the remaining distal joints together. The merus is about as long as the propodus, which is longer than the carpus. The dactylus is one-half as long as the propodus. The merus has two teeth on the outer edge and six teeth and hairs on the inner.

The basis of first peraeopod is stout, and as long as the remaining distal joints together.

The peduncle of uropod is about two and three-fourths times as long as the sixth abdominal segment and furnished with four short and four long plumous hairs on the inner edge and small serrations on the outer. The endopod is more than one-half as long as the peduncle and has a long and two short terminal setae, seven spines interspaced with spinules on the inner edge and about eight spinules on the outer. The exopod is a little shorter than the endopod and furnished with a long and a short terminal setae and a spine on the inner edge and three spines on the outer.

Remarks: The new species is related to C. canaliculata ZIMMER (ZIMMER '36), C. latydactyla HALE, C. minor HALE (HALE, '45), C. sulcata SARS (SARS 1900) and C. tubulata FAGE (FAGE' '45).

These may be distinguished from the new species as follows: In C. canaliculata and C. latydactyla the end of dactylus of second peraeopod is rounded; the pseudorostral lobes of male of $C$. minor are subtruncated and concave in front; $C$. tubulata has short and narrow lateral furrow on each side of carapace; and $C$. sulcata has no long plumous terminal hair on the dactylus of second peraeopod.

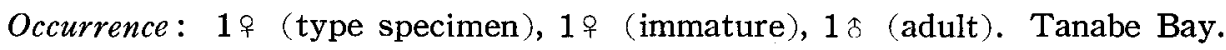

\section{LITERATURE}

FAGE, L. 1945. Les Cumacés du plankton nocturne des côtes d'Annam, Arch. Zool. éxp. et gén., T. 84, pp. 165-224, figs. 1-39.

1951. Cumacés. Faune de France, T, 54, pp. 1-136, Paris.

Hate, H. 1945. Australian Cumacea. No. 9. The Family Nannastacidae, Rec. S. Aust. Mus., vol. 8, pp. 145-217, figs. 1-49.

SARS, G. O. 1900. Cumacea. An Acount of Crustacea of Norway, vol. III, pp. i-v, 1-115. pls. ILXX.

Zimmer, C. 1936. California Crustacea of the order Cumacea. Proc. U. S. Nat. Mus., vol. 83, No. 2992 , pp. $423-439$, figs. 1-39. 